\title{
EVALUATION OF ORGANIZATIONAL STRUCTURE IN EMERGENCY FROM THE VIEWPOINT OF COMMUNICATION
}

\author{
S. Nishida, M. Nakatani, Y. Hijikata, and T. Koiso \\ Department of Systems and Human Science, Graduate School of Engineering Science \\ Osaka University, Toyonaka, Osaka, 560-8531 JAPAN \\ nishida@sys.es.osaka-u.ac.jp
}

\begin{abstract}
This paper focuses on evaluation of organizational structure in emergency from the communication viewpoint. The communication process in emergency is analyzed first, and the problems caused in the process are discussed. Then a communication model is proposed, in which human related factors such as "competence", "duty", "responsibility" and "knowledge" are considered. Then a system to evaluate onganizational structure in emergency from the viewpoint of communication is designed on the basis of the model. Finally, a prototype system with GUI is developed and its evaluation results are discussed.
\end{abstract}

\section{INTRODUCTION}

It is frequently observed in the emergent situation that important information does not reach to an appropriate person or department in the organization because of the confusion after the emergency or in some case because of lack of knowledge on contact address. This phenomenon happens especially when the size of organization becomes large, and we believe it is very important to predict communication problems in advance and improve the organizational structure from the viewpoint of communication.

Several types of communication models have been studied in the field of CSCW (Computer-Supported Cooperative Work). For example, conversation model based on the Speech Act Theory was developed (Winograd, 1988) and Dit is used for a support system which deals with E-mail processing. The IBIS (Issue Based Information System) model was proposed (Conklin, et al., 1988) and it is used for a support system to enhance software productivity. Furthermore, trouble communication model in software development project was studied (Nakatani, et al., 1992)

In this research, we first investigate in the important factors in emergent situations and propose a communication model in emergent situation in which human related factors such as "competence", "duty", "responsibility" and "knowledge" are focused. Then a system to evaluate organizational structure in emergency from the viewpoint of communication is proposed based on the model. 
Finally, a prototype system with GUI is developed and its evaluation results are discussed.

\section{ANALYSIS OF DECISION MAKING IN EMERGENCY}

Recently, "commandware" is recognized to be very important in the field of crisis management. (Kawata, 1995) "Commandware" is regarded as the chain of commands to manage emergent situations. Commandware is closely related to the structure of organization. Hierarchical structures are usually adopted for the large scale system such as fire department, police system, management system for large scale chemical plants, and so on. In the hierarchical structure, problem solving is conducted by mutual communication among the nodes in the hierarchy.

Here we made interviews to the people who manage large scale plants such as power plant etc. to investigate how decisions or judgments are conducted and what types of communications occur in emergent situations. Concretely, we asked what type of communications occurred, and what was the objective of the communication. By summarizing these data, we reached to the conclusions that many communications, which were observed in plant management, are caused by the following factors.

(1) Who is the person that has competence to execute the operation?

(2) Who is the person that must execute the operation?

(3) Who is the person that takes responsibility for assuring some results on the troubled situation?

(4) Who is the person that has knowledge on the current situation or on the actions to be taken?

The above factors are called as "human related factors", and it is thought that they play a very important role in selecting proper actions in the judgment process. The human related factors are the causes of communications between each node in the hierarchy, and the destination or the quantity of the communication depends on the human related factors. Though little attention has been given to the communication caused by these factors so far, we recognized the importance of the human related factors through the analysis of the interviews to the fire department.

\section{COMMUNICATION MODEL IN EMERGENT SITUATION}

In this section, a communication model is introduced in which human related factors are considered. The following four types of the communications generated at each node of the hierarchical organization are considered here.

(1) Communication generated by competence

It is defined as the communication to get permission of executing some operation, since the person has no competence, that is, no right to execute the operation. 
(2) Communication generated by duty

It is defined as the communication to contact to the other person who has the duty to execute some operation under a given situation, since current situation is thought to need the operation and the person has no duty of executing it.

(3) Communication generated by responsibility

It is defined as the communication to contact to the other person who has the responsibility to execute some operation for assuring some results, since the person has no responsibility on it. Here responsibility means to assure the results by taking any means.

(4) Communication generated by knowledge

It is defined as the communication to contact to the other person who knows the situation or the operation very well, since the person does not know it well.

Our communication model in emergent situations consists of the above four types of basic communications, and the model is composed of both "physical structure" of the large scale system and "human related factors" in it. Figure 1 shows the concrete components of physical structure and human related factors. Physical structure is decided by the structure of artifacts. Physical structure is divided into four sub- structures as follows:

(a) Plant Structure (PS): PS shows names, location of each part.

(b) Sensor Structure (SS): SS shows sensor name, location, measurement and values.

(c) Actuator Structure (AS): AS shows actuator name, location and type of actuator.

(d) Trouble Operation Structure (TOS): TOS shows the relation between trouble situation, action to be taken and result of the action.

\begin{tabular}{|c|c|c|c|c|c|}
\hline \multicolumn{3}{|c|}{ [Physical Structure] } & \multicolumn{3}{|c|}{ [Human Related Factors] } \\
\hline $\begin{array}{l}\text { (a) Plant Structure } \\
\text { (b) Sensor Structure } \\
\text { (c) Actuator Structur } \\
\text { (d) Trouble Operatio }\end{array}$ & Structure & $\begin{array}{l}\text { (PS) } \\
\text { (SS) } \\
\text { (AS) } \\
\text { (TOS) }\end{array}$ & $\begin{array}{l}\text { (e) Organization S } \\
\text { (f) Competence St } \\
\text { (g) Duty Structure } \\
\text { (h) Responsibility } \\
\text { (i) Knowledge Str }\end{array}$ & $\begin{array}{l}\text { cture } \\
\text { ture } \\
\text { ucture } \\
\text { ure }\end{array}$ & $\begin{array}{l}\text { (OS) } \\
\text { (CS) } \\
\text { (DS) } \\
\text { (RS) } \\
\text { (KS) } \\
\end{array}$ \\
\hline \multicolumn{6}{|c|}{ [Inference Mechanisms] } \\
\hline $\begin{array}{c}\text { Communication } \\
\text { generated by } \\
\text { Competence }\end{array}$ & $\begin{array}{r}\text { Commun } \\
\text { generate } \\
\text { Dut }\end{array}$ & $\begin{array}{l}\text { ication } \\
\text { ed by } \\
\text { y }\end{array}$ & $\begin{array}{l}\text { Communication } \\
\text { generated by } \\
\text { Responsibility }\end{array}$ & \multicolumn{2}{|c|}{$\begin{array}{l}\text { Communication } \\
\text { generated by } \\
\text { Knowledge }\end{array}$} \\
\hline
\end{tabular}

Figure 1 Communication Model 
These sub-structures are determined by the physical factors of the system, and it is independent of the human related factors. On the other hand, the human related factors are concerned with competence, duty, responsibility and knowledge. The factors are determined by the formation of organization, bylaw related to persons, each person's knowledge and so on. The human related factors are expressed by the following five sub-structures:

(e) Organization Structure (OS): OS shows names of each person in the organization and location of hierarchical organization.

(f) Competence Structure (CS): CS indicates persons who can execute some actions to be taken.

(g) Duty Structure (DS): DS indicates persons who must execute some action to be taken in the trouble situation.

(h) Responsibility Structure (RS): RS indicates persons who assure some results for the trouble situation.

(i) Knowledge Structure (KS) : KS indicates persons who know the part of physical structure well.

Adding these structural data, the model has inference mechanism to predict "who has the competence on the operation?" "Who has the duty on the given troubled situation?" and so on. When some situation is given as an input, the destination of each type of communication mentioned before is determined by the following inference mechanisms based on the physical structure and the human related factors.

(1) Communications generated by competence

Some appropriate actions to be taken under a given situation are selected from TOS. Then persons who have competence for the selected actions are predicted from CS, and the destination of communication generated by competence is decided.

(2) Communications generated by duty

Some appropriate actions to be taken for the given situation is selected from TOS. Then persons who have duty on the trouble situation and the selected actions are calculated from DS. The derived persons correspond to the destination of communication generated by duty.

(3) Communications generated by responsibility

Some appropriate actions to be taken and results of the action under the given situation are selected from TOS. Then persons who have responsibility for the trouble situation and assumptive results are predicted from RS. The derived persons correspond to the destination of communication generated by responsibility.

(4) Communications generated by knowledge

Some parts of the plant concerned with given situation are selected from SS, or some appropriate actions to be taken under the given situation are selected from TOS. Persons who have information on the part selected by SS are calculated from KS. Moreover, persons who have information on the selected actions are also 
calculated from KS. The destination of communication generated by knowledge is decided in this way.

As a total, the communication model in emergent situations can predict the destination of four types of basic communications by symbol processing using the data of both physical structure and the human related factors, when the situation of the system is given as an input.

\section{A PROTOTYPE SYSTEM TO EVALUATE ORGANIZATIONAL STRUCTURE FROM THE VIEWPOINT OF COMMUNICATION}

A prototype system to evaluate organizational structure in emergency is developed based on the above communication model.

The system can deal with four types of communications, that is, communication generated by competence, communication generated by duty, communication generated by responsibility and communication generated by knowledge. Figure 2 shows an example data for the prototype system. The structure of organization is assumed to be two layer hierarchy. The member which corresponds to root node is " $\mathrm{C}$ " and the two members which correspond to leaf nodes are "A" and "B". The physical plant consists of two plants, "Pa" and " $\mathrm{Pb}$ ". $\mathrm{Pa}$ is composed of four parts and has seven sensors and four actuators. $\mathrm{Pb}$ is composed of two parts and has three sensors and two actuators.

(a) organization structure

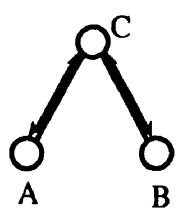

(b) plant structure

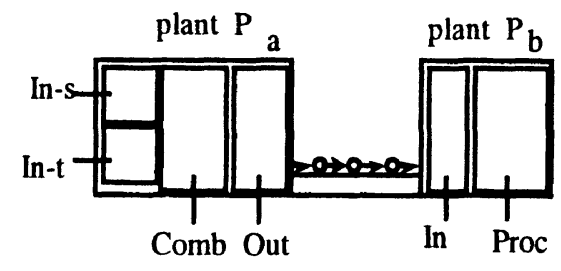

Figure 2 An Example Data 
Parameters of sensors take values of "H(igh)", "M(iddle)" and "L(ow)". Parameters of actuators take values of "U(p)" and "D(own)".The data of the prototype system are managed by the frame-type data. For example, Plant Structure (PS) data "pnm, 1, Pa, In-s" means that the part "In-s " in the plant "Pa" is defined as "No.1" Plant Structure data. By using these nine types of data, destination of each kind of communication, which is generated from competence, duty, responsibility and knowledge, is determined by the mechanism mentioned in the section of communication model.

By using this system, we can find communication problems for the current organization structure, and also we can search improved organizational structure from the viewpoint of communication. The following functions are provided in the prototype system.

(1)Visualization of communication frequency distribution

By using the communication model in emergency, we can calculate the frequency of communications caused by some accidents in the physical system. If the probability of each accident is given in advance, then the communication frequency in the organization is calculated and it is visualized in the system.

(2)Detection of communication bottlenecks

The "communication bottlenecks", which have high possibility to receive many communications in emergency, can be predicted in the system. Furthermore, by changing human related factor data, we can find a new improved organizational structure.

(3)Comparison of different organizational structures

If the different organizational structures are given to the system, we can compare the structures from the viewpoints of communication and evaluate which structure is better. For example, hierarchical structure and flat structure can be compared quantitatively from the communication viewpoint.

The prototype system is developed on the PC using JAVA language. Figure 3 shows the comparison between hierarchical structure $S 1$ and flat structure S2. In S1, communications are concentrated on $\mathrm{E}$ and $\mathrm{F}$, however, in S2, there is no concentration. On the other hand, S1 has higher extension index value than $S 2$, which means that $S 2$ is more distributed organization than S1.

\section{CONCLUSIONS}

In this paper, decision-making in emergent situations is analyzed, and the important factors are investigated from the viewpoint of communication. Then communication model which considers human related factors such as "competence", "duty", "responsibility" and "knowledge", is introduced and a prototype system to evaluate organizational structure in emergency is developed based on the communication model.

We plan to try more complex examples in the next stage, and to improve the function of the evaluation system. 


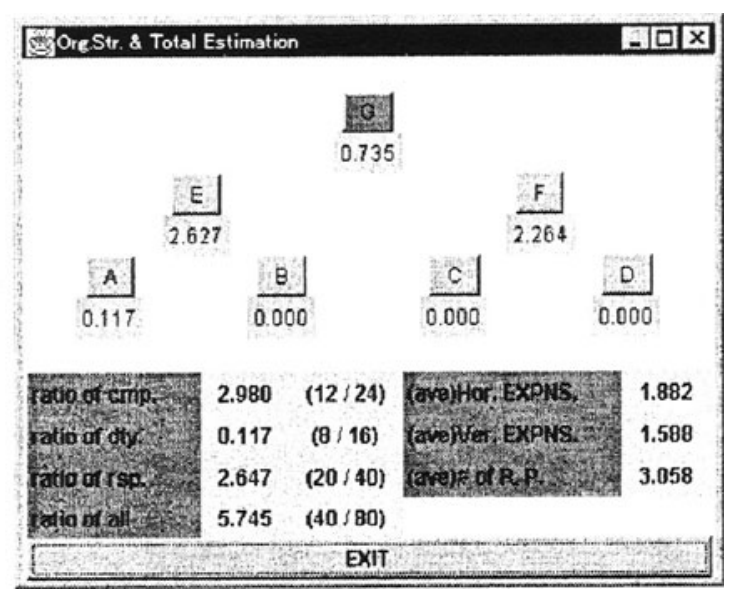

(a) Hierarchical Structure S1

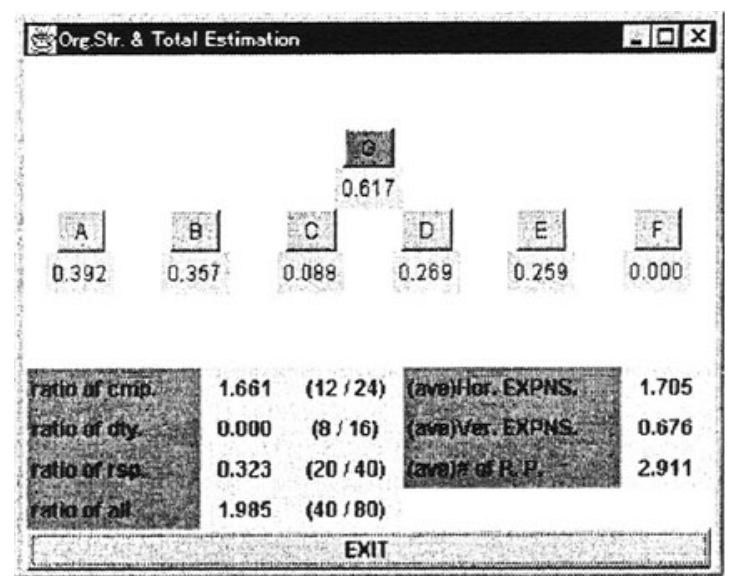

(b) Flat Structure $\mathrm{S} 2$

Figure 3 Evaluation Results

\section{ACKNOWLEDGEMENTS}

This work was partially supported by the JapanDSocietyDfor the Promotion of Science under Grant-in- Aid for Creative Scientific Research ( Project No. 13S0018) 


\section{REFERENCES}

1. Koiso, T. and Nishida, S: Communication Support System for Operators in Emergency of Large Scale Plant, Proceedings of INCOM'98, pp.491-496. 1998.

2. Kawata, Y.: " Catastrophic Urban Disasters", Kinmirai-sha (in Japanese), 1995.

3. Nakatani, M. and Nishida, S.: " Trouble Communication Model in a Software Development Project", IEICE Trans. Fundamentals, Vol.75-A No.2, pp.196-206, 1992.

4. Nunamaker, J..F.: editor, Special issue on GDSS, Decision Support Systems, 5(2).1989.

5. Conklin, J. and Begeman, M.L.:" gIBIS : A Hypertext Tool for Exploratory Policy Discussion", Proceedings of CSCW'88, pp.140-152, 1988.

6. Winograd, T.: "A Language Perspective on the Design of Cooperative Work.", Proceedings of CSCW'88. pp203-220, 1988.

7. Malone, T.W. "Modeling coordination in organizations and markets, Management Science", 33(10), pp.1317-1332, 1987. 